\title{
Polio in Nigeria
}

Elisha P. Renne*

University of Michigan

\section{Abstract}

Poliomyelitis, or polio as it is commonly known, is a disease caused by an enterovirus found throughout the world. Although it is often associated with paralysis of one or more limbs, it is more common for children to experience asymptomatic cases of the disease, which convey lifelong immunity. While lameness associated with polio has long been known in Nigeria, during the colonial period immunization efforts focused mainly on expatriates. Later, with the implementation of the Expanded Programme on Immunisation during the 1980s, polio vaccination was included as part of primary health care. However, it was only after the 1988 World Health Assembly vote to eradicate polio worldwide that intensive efforts to vaccinate all children under five for polio began. Initial efforts, which focused only on polio vaccination, may be characterized as an "override approach." In 2006, Nigeria had the greatest number of confirmed cases of polio worldwide. However, with the implementation of a more "collaborative approach," incorporating other vaccines and health incentives such as bed nets, the number of polio cases declined. By the end of 2010, case numbers had declined dramatically and these numbers remain low, reflecting government, NGO, and community efforts to work together to end polio transmission in Nigeria.

The focus on polio in Nigeria over the past two decades reflects member nations' vote at the $41^{\text {st }}$ World Health Assembly meeting held in Geneva in 1988 to eradicate the disease worldwide by $2000 .{ }^{1}$ Initially implemented in 1995 in Nigeria, the Polio Eradication Initiative exemplifies what Amartya Sen refers to as an "override" approach. ${ }^{2}$ By ignoring local concerns and related national and international issues while assuming that the virtues of disease eradication - of which there are many - would trump all others, the initiative foundered. In 2006, the program was revamped to incorporate community health concerns. ${ }^{3}$ This review considers the historical context and the specific factors which have led to a dramatic decline in confirmed cases of polio in 2010 (Table 1). While government and health officials had hoped that Nigeria would be polio-free by 2011, sixty-two wild poliovirus cases were confirmed that year, all in northern Nigerian states (Fig. 1). ${ }^{4}$

This situation suggests that some of the underlying political, social, and economic problems besetting this global public health campaign persist. Indeed, in 2011 presidential/gubernatorial elections and subsequent post-election violence, as well as ongoing conflict between government officials, state/federal military police, and members of a fundamentalist Islamic group in Borno State (in northeastern Nigeria) have hampered, but not stopped, polio eradication and broader immunization efforts.

\section{Early Documented Experiences of Polio in Nigeria}

Polio has long been recognized in Nigeria and has several names which reflect local understandings of its symptoms or causes-arun aromolapa romolese (literally, disease that cripples a child's hands and legs: Yoruba) in the southwest; and öria ngwulö (disease that 
Table 1. Cases of Acute Flaccid Paralysis (AFP) and Confirmed Cases of Wild Poliovirus and Circulating Vaccine-Derived Poliovirus, Nigeria, 1999-2011 (as of 31 December 2011)

\begin{tabular}{lllllll}
\hline Year & $\begin{array}{l}\text { AFP } \\
\text { cases } \\
\text { reported }\end{array}$ & $\begin{array}{l}\text { Non-polio } \\
\text { AFP rate }\end{array}$ & $\begin{array}{l}\text { AFP cases- } \\
\text { w/adequate } \\
\text { specimens } \%\end{array}$ & $\begin{array}{l}\text { Total } \\
\text { confirmed } \\
\text { polio cases }\end{array}$ & $\begin{array}{l}\text { Wild-virus } \\
\text { confirmed } \\
\text { polio cases }\end{array}$ & $\begin{array}{l}\text { Vaccine-derived } \\
\text { confirmed } \\
\text { polio cases }\end{array}$ \\
\hline 1999 & 1242 & 0.5 & 26 & 981 & 98 & - \\
2000 & 979 & 0.7 & 36 & 638 & 28 & - \\
2001 & 1937 & 3.8 & 67 & 56 & 56 & - \\
2002 & 3010 & 5.7 & 84 & 202 & 202 & - \\
2003 & 3318 & 6.0 & 91 & 355 & 355 & - \\
2004 & 4814 & 8.0 & 91 & 782 & 782 & - \\
2005 & 4836 & 6.3 & 85 & 831 & 830 & 1 \\
2006 & 5175 & 6.5 & 88 & 1143 & 1122 & 21 \\
2007 & 4277 & 5.9 & 94 & 353 & 285 & 68 \\
2008 & 5536 & 6.5 & 93 & 861 & 798 & 63 \\
2009 & 5501 & 7.1 & 95 & 541 & 388 & 153 \\
2010 & 5996 & 8.6 & 95 & 48 & 21 & 27 \\
2011 & 6099 & 8.6 & 94 & 95 & 62 & 33 \\
\hline
\end{tabular}

Source: WHO 2012 http://www.who.int/immunization_monitoring/en/diseases/poliomyelitis/case_count. cfm.

(accessed 19 April 2012).

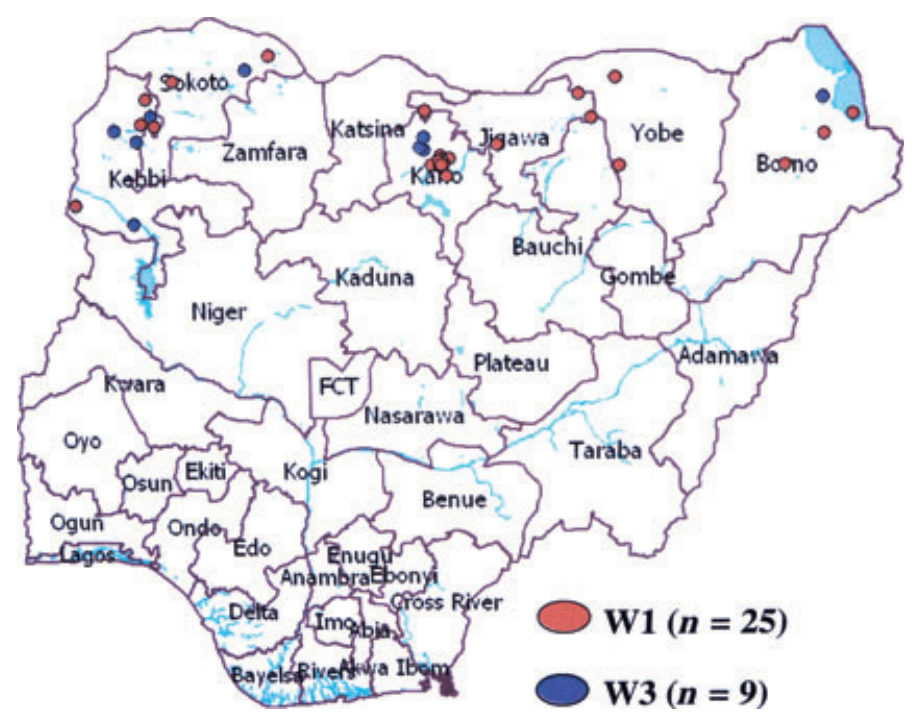

Fig. 1. Map of Nigeria, by state with polio distribution, 2011 (UNICEF/polioinfo website, http://www. polioeradication. org).

causes paralysis of limbs, lameness; Igbo) in the southeast; and cutar Shan Inna (literally, disease caused by the drinking of Inna: Hausa) in the north.

In the late 1950s and after Independence, during the early 1960s, researchers began to study the prevalence of poliomyelitis among Nigerians. ${ }^{5}$ An increasing incidence of polio among expatriates during the 1950 s led to a growing concern with polio vaccination, which the introduction of the Salk polio vaccine made possible. This situation developed as a consequence of the particular epidemiology of the poliovirus. For those who had 
grown up in hygienic environments where exposure to poliovirus was unlikely, as in Great Britain during the early $20^{\text {th }}$ century and where prior immunity had not been obtained, it was possible to contract acute cases of paralytic polio that were life-threatening, particularly to adolescents and adults since the severity of paralysis increased with age. 6 During the first six months of 1956, "six adult Europeans" contracted polio in Lagos and at least two expatriates died from polio. ${ }^{7}$ In July 1956, the Colonial Office instituted a scheme for vaccinating expatriates working in Nigeria.

At the same time, clinical studies of polio immunity were carried out in Nigeria-in Lagos (Lagos State), Oloibiri (Niger Delta), and Kadandani (Katsina State; Table 2). In the 1956 Kadandani study, only 33\% of children aged 6-11 months had polio antibodies. ${ }^{8}$ However by age 10,100\% had polio antibodies, acquiring what is referred to as "natural immunity," and hence were immune from the disease. Prior to immunization with the Salk injectable vaccine and later the Sabin oral vaccine, "natural immunity" was the principle means by which Nigerian children were protected from polio.

However, some children did develop polio-related paralysis. Two epidemiological studies of Nigerian children brought to University College Hospital-Ibadan with paralysis symptoms associated with polio were conducted, the first for the period from 1958 to $1960,{ }^{9}$ the second using hospital datafrom 1964 to 1973 . Familusi and Adesina found that polio was prevalent throughout the year in the Ibadan and surrounding areas, which they attributed to population increase and urban crowding. After a short-lived polio vaccination program in Ibadan carried out by the World Health Organization in 1974, the number of polio cases declined, leading Familusi and Adesina to advocate for a regular vaccination program for the disease. ${ }^{10}$

\section{The Expanded Programme on Immunisation and Polio Vaccination}

This advice to vaccinate Nigerian children for polio was not taken up nationally until 1988 when the Nigerian government, with the assistance of UNICEF, implemented the Expanded Programme on Immunisation, under the leadership of Professor Olikoye Ransome-Kuti. The program began with the opening of primary health care centers across the country. ${ }^{11}$ According to this global health program, vaccines for six early childhood diseases-diphtheria, tetanus, whooping cough, measles, polio, and BCG vaccine (for tuberculosis) - were to be given to more than $80 \%$ of Nigerian children. ${ }^{12}$ With the exception of BCG (Table 3), this high level of immunization was never been achieved, although efforts to immunize children at Primary Health Care centers contributed to improvements in overall immunization. However, due to political and economic factors, after 1990, the federal government transferred the administration (and funding) of the EPI program and primary health care more generally to individual states, after which immunization levels declined, with levels as low as 30\% coverage reported in some states. $^{13}$ According to WHO-UNICEF estimates, country-wide immunization for polio (three doses) stood at 26\% in 1996 (Table 3). This was the situation when the Nigerian government began its participation in the program to eradicate polio worldwide.

\section{The Polio Eradication Initiative}

After the successful eradication of smallpox, certified in 1980, international public health officials considered other diseases that could follow. Because an effective vaccine, protocol for vaccine delivery and case testing for poliomyelitis had been established, it was decided that polio should be targeted for eradication. The World Health Assembly voted to 


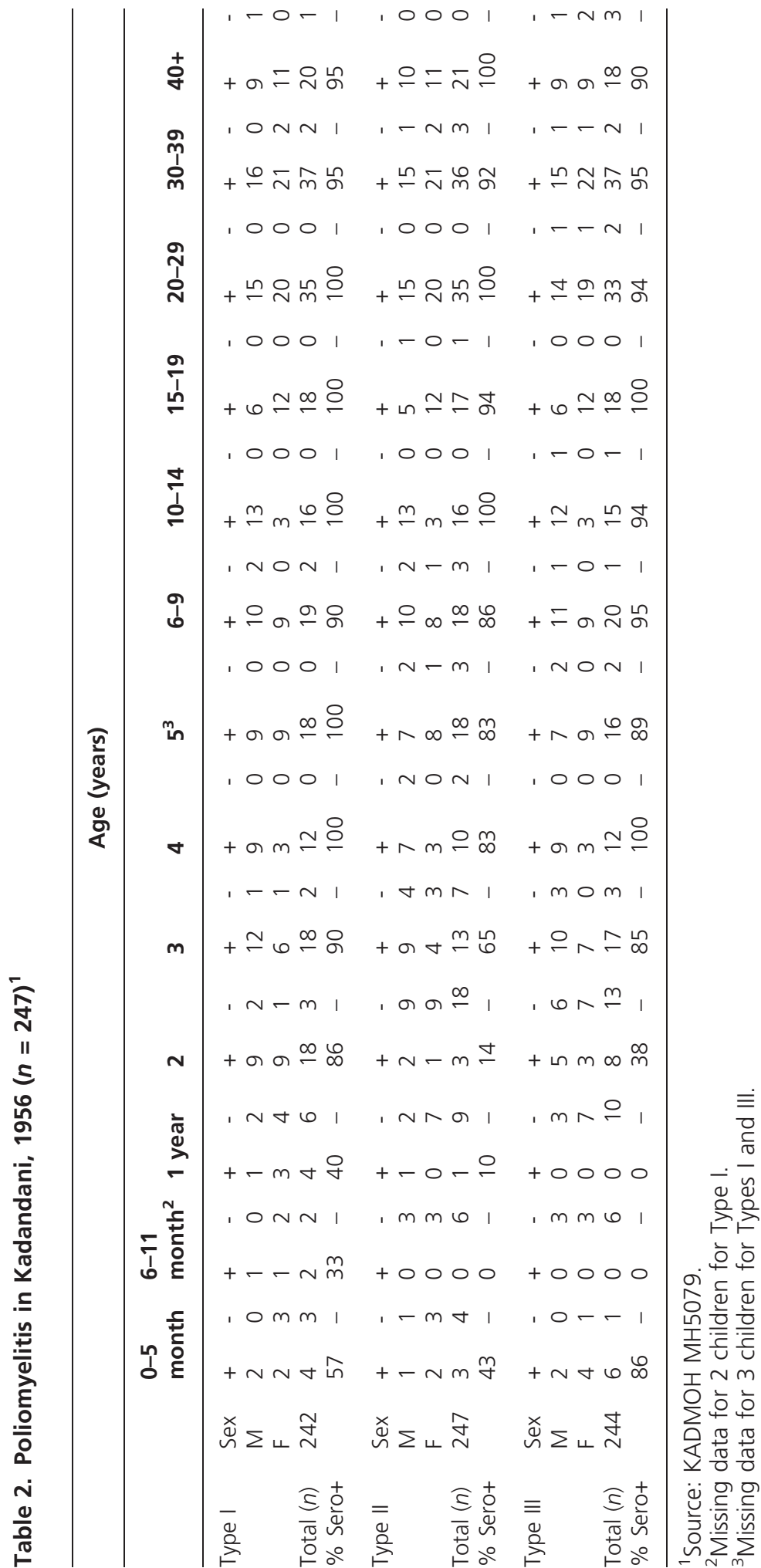




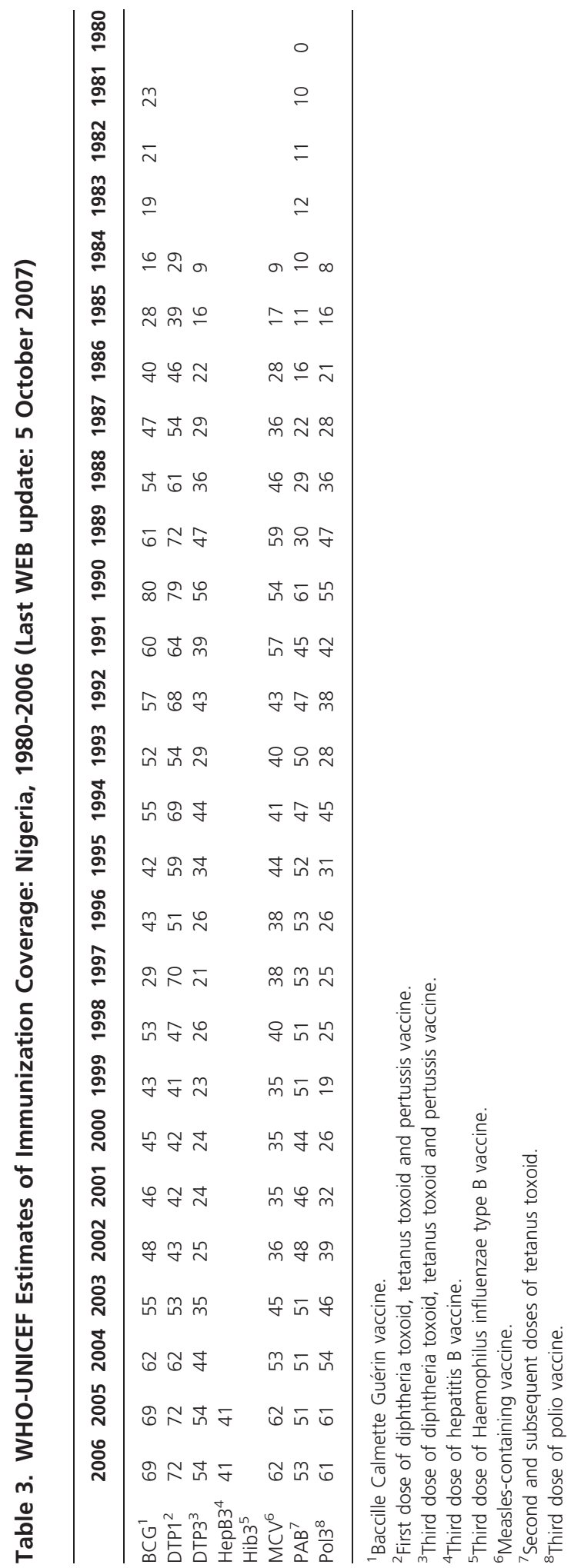


implement the Polio Eradication Initiative in 1988. Member states were directed to work to eradicate poliomyelitis with the understanding "that achievement of the goal will depend on the political will of countries and on the investment of adequate human and financial resources."14

In Nigeria, this political will has waxed and waned. In July 1995, the Expanded Programme on Immunisation was renamed the National Programme on Immunization (NPI) and in 1996, this program was formally launched by the former First Lady, Miriam Abacha. The NPI was responsible for conducting the polio initiative although it was affected by political appointments as well as disinterest on the part of some local politicians and health officials, factors which impeded the program's work. ${ }^{15}$ These political aspects of the campaign may be seen in Kano, the most populous metropolitan center in northern Nigeria, which was and continues to be the epicenter of continued wild poliovirus transmission. Much has been written about the former Governor Ibrahim Shekarau's ban of polio immunization in Kano State in October 2003 due to uncertainty over its safety. However, other factors affected parents' willingness to vaccinate their children for polio which was widely seen as a foreign health intervention. ${ }^{16}$ In January 2006, the newly appointed acting director of the NPI, Dr. Edugie Abebe, sought to address health and safety concerns by implementing a program called Immunization Plus Days (Fig. 2), which provided parents with a

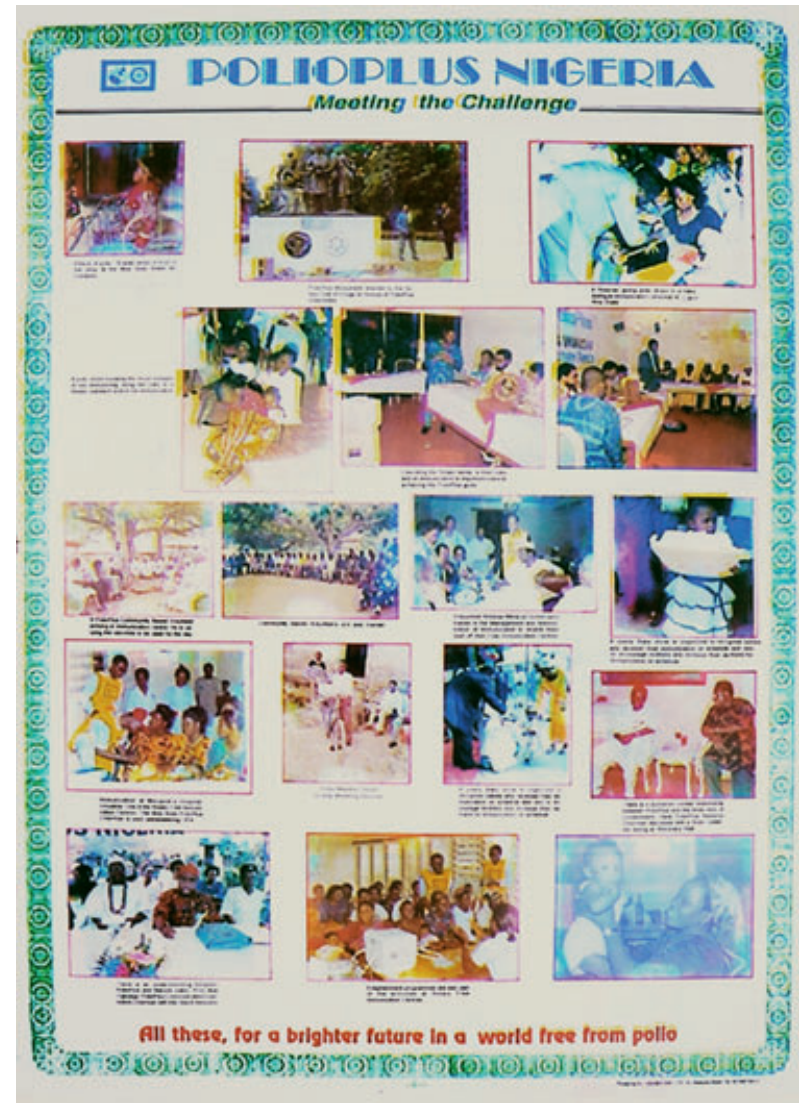

Fig. 2. Immunization Plus Days poster, Nigeria, 2006 (Courtesy of Rotary International, from Smithsonian Institution website exhibition, "Whatever Happened to Polio?"), http://americanhistory.si.edu/polio/poliotoday/immunization. htm, accessed 18 May 2012. 
range of health incentives, including bed nets, measles vaccination, and deworming tablets. ${ }^{17}$

This program was popular and consequently the number of confirmed cases of polio virus declined from 1,122 cases in 2006 to 285 cases in 2007 (see Table 1). However, political considerations again intervened and when the National Programme on Immunization was merged with the National Primary Health Care Development Agency (NPHCDA), Dr. Abebe resigned. The NPHCDA director who took over the polio immunization program was inexperienced; funds ran out for bed nets and once again there was an increase in cases. By the end of November 2008, Nigeria reported 758 confirmed cases, the greatest number of wild poliovirus cases in the world. ${ }^{18}$

\section{Changes in Nigerian Polio Eradication Efforts}

However, several political decisions made at the end of 2008 contributed to a significant improvement of polio eradication efforts in Nigeria. In October 2008, Dr. Muhammad Ali Pate, was appointed as the new NPHCDA executive director. Not only was Dr. Pate an experienced health official who had worked with the World Bank, he was also a northerner who was sympathetic to the concerns of northern Nigerian parents. ${ }^{19}$ One month later, Professor Babatunde Osotimehin was appointed as the Ministry of Health. Together they worked with members of the Expert Review Panel to revamp the polio immunization program. While focusing on polio, health officials also incorporated a range of health incentives along with an emphasis on community communication and improvements in primary health care provision. This change in perspective was reflected in the Expert Review Committee's conclusion that "The growing national and state level commitment to polio eradication and immunization must be taken down to local government and community level." 20 The October 2008 report also proposed plans for strengthening national immunization campaigns in order to maintain polio-free zones in midwestern and southern states, while improving overall immunization levels in the north, particularly in the six endemic states-Kano, Zamfara, Katsina, Kaduna, Bauchi, and Jigawa-where the transmission of wild poliovirus had not been interrupted ${ }^{21}$

Dr. Pate's organizational leadership also contributed to increased use of health incentives, as had been successfully employed during Immunization Plus Days (IPDs) begun in 2006. Along with IPDs which tended to focus on high risk areas, the program continued with National Immunization Days and Sub-National Immunization Days, the latter carried out in endemic areas where they were sometimes extended to continue for several weeks. These "Days" also incorporated new methods, such as the use "of 'transit teams' to vaccinate children on public and private transport, and the use of 'street teams' to cover children in playgrounds and other areas outside the household." 22 The massive immunization efforts in 2009 contributed to significant decline in confirmed cases of wild poliovirus in Nigeria that year. By the end of October 2009, there were 388 cases, about half of the 796 cases reported at the same time the previous year. For the year 2010, there were only 21 cases of wild poliovirus reported for the entire country (see Table 1). ${ }^{23}$

\section{Other Factors Contributing to the 2010 Decline}

While this steep decline in the number of polio cases reflected greater levels of immunity among more Nigerian children due to changes in program leadership and improved immunization campaigns, there were other factors-social, medical, institutional, 
technical, and legal - that contributed to more parents agreeing to have their children immunized, particularly in northern Nigeria.

In June 2009, Alhaji Muhammad Sa'ad Abubakar, the Sultan of Sokoto, organized a committee of fourteen northern Nigerian traditional rulers to address the continued presence of polio in the North. ${ }^{24}$ While his predecessor, Alhaji Muhammadu Maccido, had also supported the campaign, the new Sultan's relative youth and conviction that northern Nigerians should not be seen as "backward" energized his efforts to get traditional rulers as well as religious leaders involved. His leadership contributed to an increased acceptance of the polio eradication initiative by many who had rejected it before.

In November/December 2008, polio vaccines were given in conjunction with a national integrated measles campaign, with follow-up vaccination days in high risk areas, which reflected a shift in emphasis, from polio to measles (Fig. 3). ${ }^{25}$ Since measles was considered by many northern Nigerian parents as a greater health risk to their children, this change demonstrated an acknowledgment of local concerns. The increased distribution of bed nets also reflected an appreciation of parents' fears about malaria. A more organized system for bed net distribution was developed in 2010. Mothers who had brought their children for polio immunization received a slip that entitled them to two bed nets, which were distributed at local sites by health officials (Figs 4, 5). The popularity of bed nets contributed to increased immunization as well.

In addition to organizing traditional and religious leaders and improving the distribution of health incentives, state commissioners of education were encouraged to implement immunization requirements for children attending nursery and primary schools. In Kaduna State in May 2009, for example, a letter went out to all school principals, noting that children five years and under needed to participate in immunization exercises when

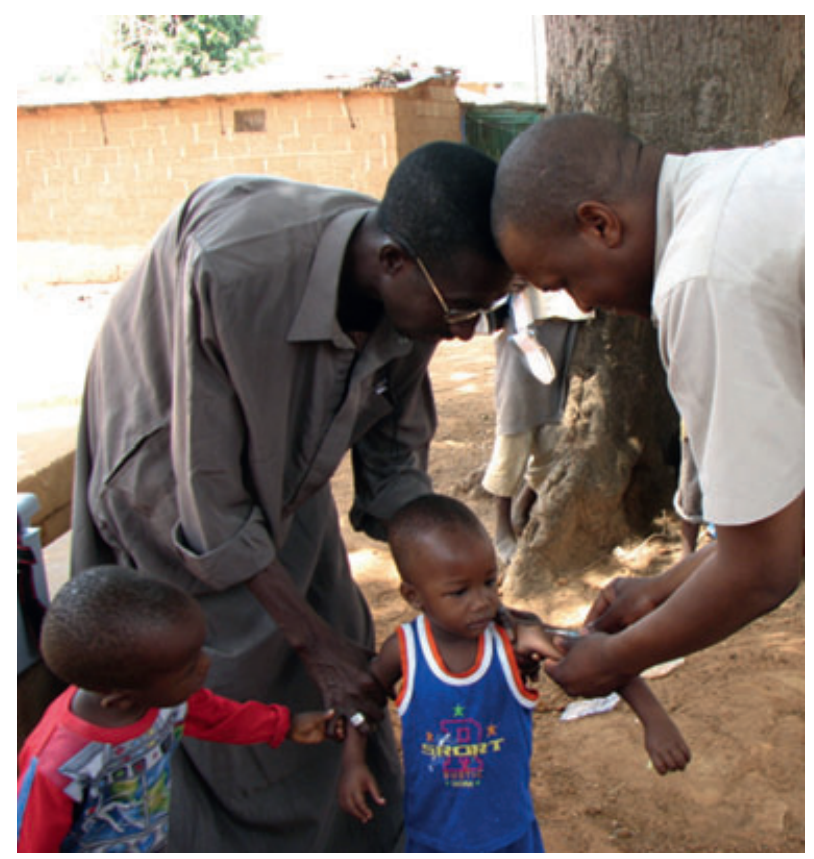

Fig. 3. Young boy received measles vaccination during supplemental National Immunization Days, Zaria, 1 June 2009 (photograph by E.P. Renne). 


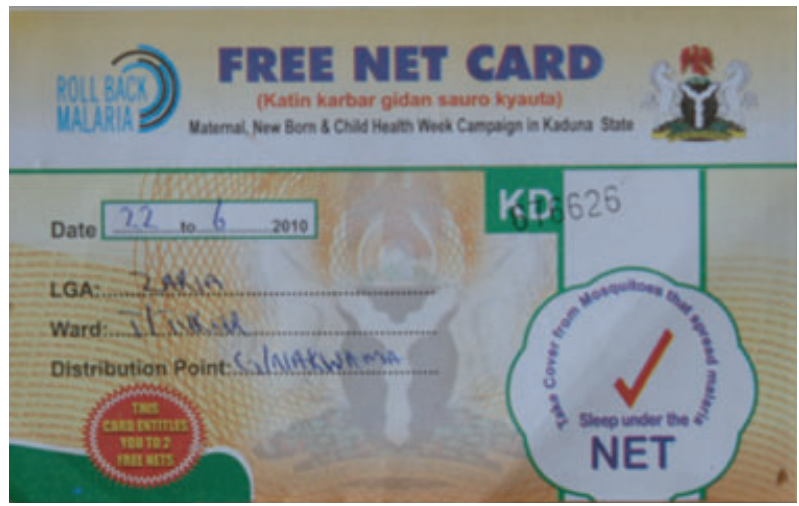

Fig. 4 Bednet slip distributed as part of immunization plus days in June 2010 (photograph by E.P. Renne).

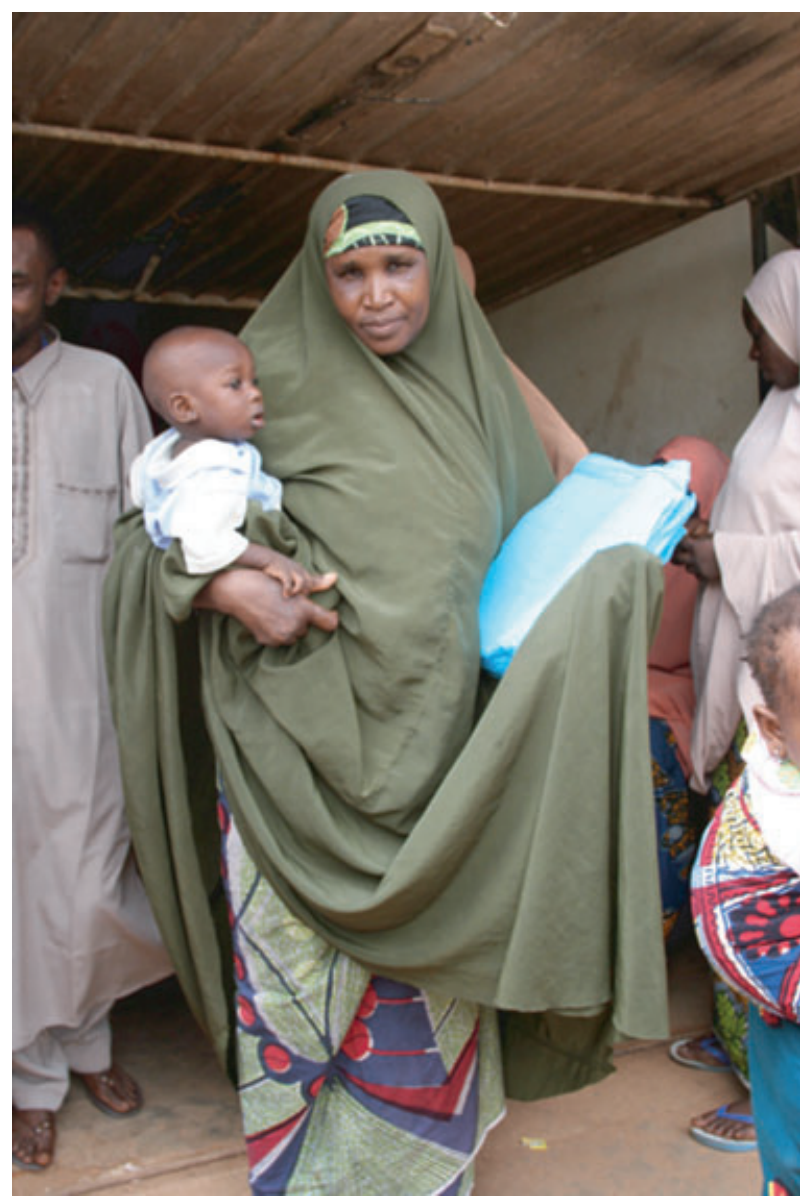

Fig. 5. Bednet distribution, 29 June 2010, Zaria (photograph by E.P. Renne).

immunization personnel visited their schools (Fig. 6). In one school, 45 out of 50 children were immunized, although some parents objected to this program and wrote letters requesting that their children not be immunized. ${ }^{26}$ Nonetheless, the effort to 


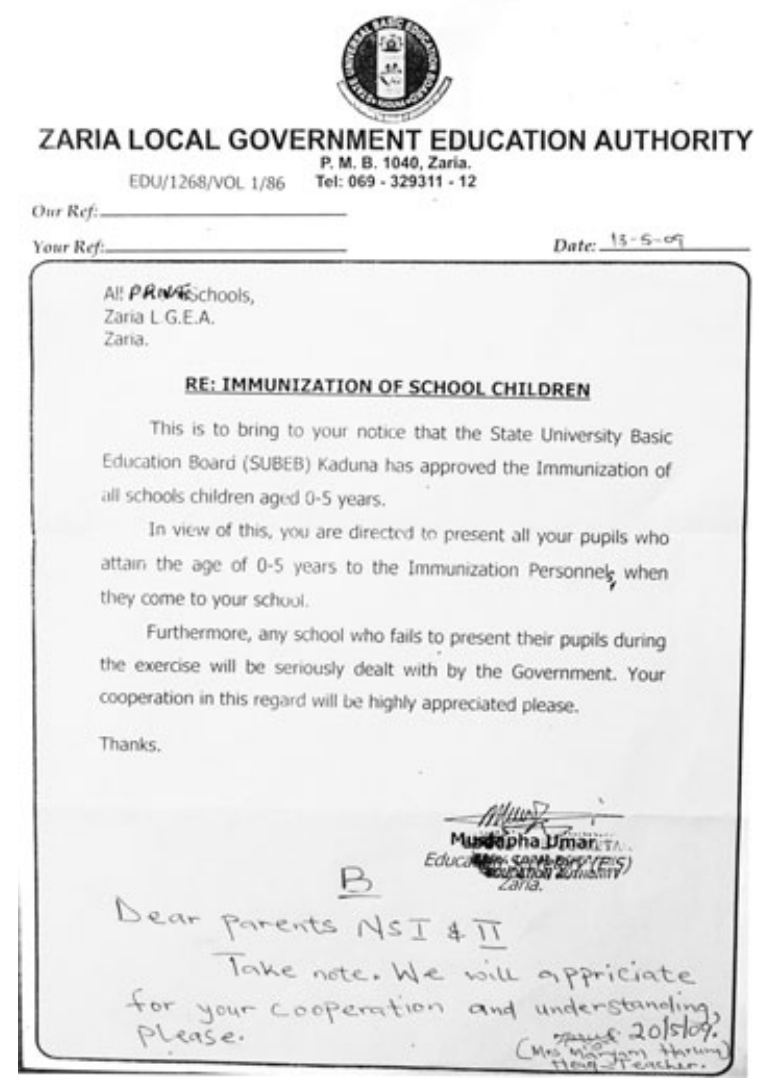

Fig. 6. Notice to school principals about immunization, 13 May 2009 (photograph by E.P. Renne).

incorporate immunization records with school attendance is part of a larger process of routinizing immunization in Nigeria.

Technical improvements in vaccines also increased immunization effectiveness. Wild poliovirus consists of three different strains, known as type 1, type 2 , and type 3 . Initially, the trivalent oral polio vaccine $\left(\mathrm{OPV}_{3}\right)$ used in the polio eradication initiative included attenuated strains of all three types. However, after 1999, when the last case of wild poliovirus type 2 was identified, efforts focused on developing vaccines that were effective against the remaining two types. Beginning in March 2006, the monovalent oral polio vaccine effective against the type 1 strain was given to children in Nigeria (Fig. 7). ${ }^{27}$ WPV-type 1 was particularly prone to spreading; in 2008, type 1 WPV polio cases were identified in twenty-three states. ${ }^{28}$ The monovalent poliovirus vaccine-type 1 more effectively provided immunity so that in 2009, rates of type 1 poliovirus declined significantly countrywide.

Finally, in January 2009, a US appeals court ruled that parents of children who had been affected by drug trial of the antibiotic, Trovan ${ }^{\circledR}$ (trovafloxacin) could sue the pharmaceutical corporation, Pfizer, Inc. ${ }^{29}$ In 1996, an epidemic of cerebrospinal meningitis occurred in mainly in northern Nigeria, with Kano State being particularly hard hit. ${ }^{30}$ Pfizer officials sponsored a trial of Trovan ${ }^{\circledR}$ at the Infectious Disease Hospital in Kano, where the oral form of Trovan ${ }^{\circledR}$ was given to approximately 100 children; another 100 


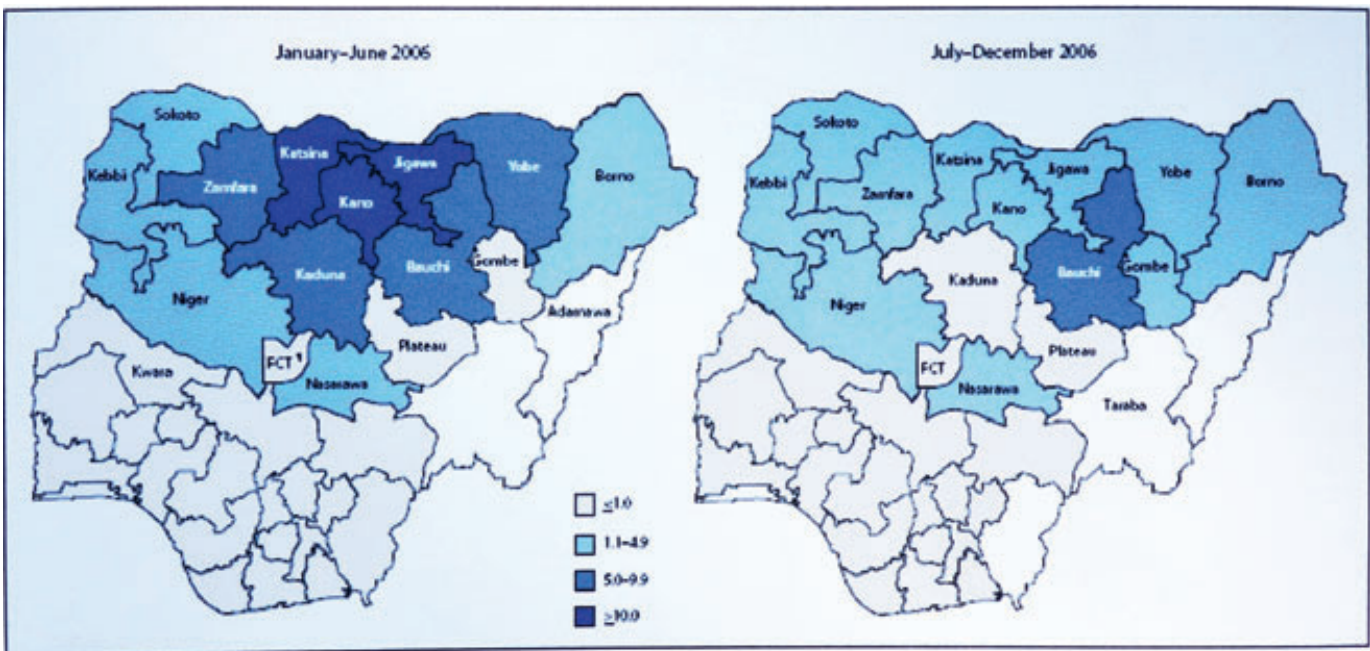

- Amnualized rate for each half year per 100,000 children aged $<5$ years.

1 Only states with reported polio cases in each half year in 2006 are labeled.

5 As of March 23, 2007.

1 Federal Cepital Territory.

\section{Source: CDC, Morbidity and Mortality Weekly Report, 56/12 (2007):281.}

Fig. 7. Rate of poliomyelitis attributed to wild poliovirus type 1, by state, in 2006, before and after mOPV1 was given (Centers for Disease Control and Prevention, Morbidity and Mortality Weekly Report 56/12 (2007): 281).

children were given the antibiotic, Cephtriaxone, the standard treatment for cerebrospinal meningitis as a control. Of the children involved in the study, eleven subsequently diedfive who had been given Trovan ${ }^{\circledR}$, six whom were given Cephtriaxone. Subsequently, a lawsuit was filed by families of the affected children in a US District Court in New York in 2002, which was initially dismissed. After several delays and adjournments, the earlier 2002 US District Court ruling was overturned and in July 2009, an out-of-court settlement for $\$ 75$ million was signed. ${ }^{31}$ Yet the consequences of this failed drug trial, locally referred to as "Pfizer," have not been forgotten in Kano, as the Kano State Commissioner for Health, Hajiya Aisha Isyaku Kiru, observed:

[She] attributed the low patronage of immunisation in the state to the drug trial carried out by Pfizer Pharmaceutical Company which was confirmed to have adverse effect on children. "Although the trial occurred years ago, it has served as deterrent to the people of the state who are still making reference to it whenever the issue of immunization comes up.",32

The legal settlement did not reverse the damage done by the drug trial, either for the parents of children who subsequently died or were severely disabled, or for the credibility of later Western health interventions. However the settlement of the case against Pfizer, which was widely reported in the northern Nigerian press, did show that Western pharmaceutical companies could be punished for their actions in Nigeria.

\section{A Few Remaining Cases, Some Continuing Problems}

The innovations in the polio eradication initiative that brought case numbers down in 2010 have continued in 2011 although there have also been setbacks in program implementation. For example, during the federal and state elections, there were "stock outs," with no vaccine availability in some health centers. ${ }^{33}$ Post-election violence, particularly 
in Kaduna State but in other northern Nigerian states as well, has also affected immunization efforts. Furthermore, difficulties in maintaining a supply of health incentives such as bed nets discouraged some parents from participating. Thus, low levels of polio immunization have persisted in some areas, along with a slight increase in confirmed cases of wild poliovirus in 2011. Two states in particular continue to present problems for polio eradication efforts in Nigeria-Kano and Borno, although transmission continues in other northern Nigerian states (Fig. 8).

Political insecurity, along with continued economic hardship, intermittent efforts at implementing earlier national health policies, and continued distrust of government programs, have hampered efforts to stop polio transmission in 2011. Yet the number of confirmed cases of wild poliovirus (62) and circulating vaccine-derived poliovirus (33) remain low, with a total of 95 cases by 31 December 2011 (Table 1). Members of the Expert Review Committee as well as Dr. Pate are promoting measles and polio immunization days as well as the improvement of national routine immunization efforts and primary health care (PHC), which Pate has referred to as "the bedrock of Nigeria's health system. $^{34}$

This policy reflects the fact that even when polio transmission has been stopped, it will still be necessary to maintain high levels of immunization against polio as well as against other childhood diseases. Health officials see improvements in routine immunization as an important part in ending polio transmission in Nigeria.

\section{Conclusion}

Earlier inattention to polio in Nigeria was followed by the polio eradication initiative, which initially focused solely on polio during a time when the primary health care system was in decline. No other diseases were included in the campaign (as had been the case

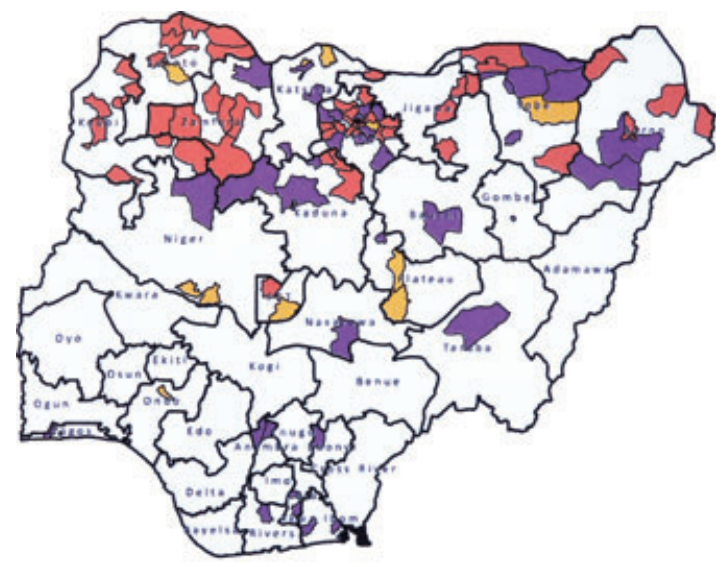

Infected with WPV/cVDPV ( 50LGAs)

Clustering of Compatibles( 12 LGAs)

Low population immunity (47LGAs)

Fig. 8. Map of Nigeria showing Local Government Areas (LGAS) with polio/polio risk/immunization levels (Courtesy of UNICEF, <http://www.polioinfo.com> website). 


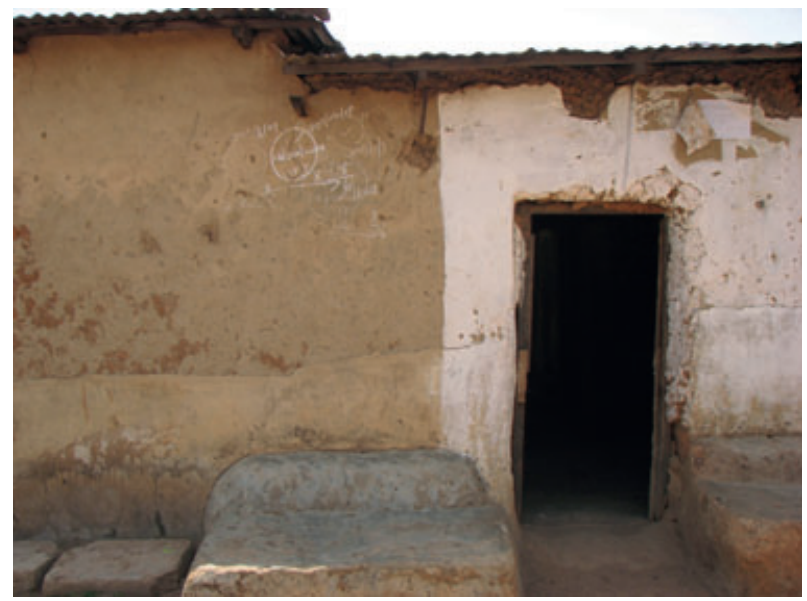

Fig. 9. Markings made on houses by polio immunization team members indicating the number of children vaccinated, Zaria, 1 June 2009 (photograph by E.P. Renne).

during the smallpox eradication program) nor were local communities consulted about the sort of health interventions they preferred. In 2006, with the subsequent reorganization of the program, which included consultation with local leaders, the inclusion of health incentives through Immunization Plus Days, ${ }^{35}$ and better monitoring (Fig. 9), the number of polio cases significantly declined. Political problems within the program interrupted this decline in 2008, but with new leadership installed in October 2008, along with the other factors discussed above, Nigeria was able to report less than 50 cases (of both wild and vaccine-derived) poliovirus in 2010. While these changes still represented an override approach in the sense that polio was the underlying focus, it nonetheless reflected a shift toward more collaborative perspective whereby local concerns about malaria and measles were also being taken into account. The increasing emphasis on collaborative efforts as well as routine immunization and improvements in village primary health care offer new hope for ending polio transmission in Nigeria. ${ }^{36}$

\section{Short Biography}

Elisha P. Renne is a professor in the Department of Afroamerican and African Studies (DAAS) and in the Department of Anthropology. Dr. Renne's interests include African ethnology and infectious disease; fertility and reproductive health; gender relations; the anthropology of development; religion and social change; and the anthropology of cloth. Her book, The Politics of Polio in Northern Nigeria, was recently published by Indiana University Press (2010).

\section{Notes}

* Correspondence: Department of Afroamerican and African Studies, and the Department of Anthropology, University of Michigan, 4700 Haven Hall, Ann Arbor, MI 48109-1045, USA. Email: erenne@umich.edu.

1 World Health Assembly. Global Eradication of Poliomyelitis by the Year 2000, Resolution WHA 41.28. Geneva: WHO, 1988 <http://www.wemos.nl/documents/WHA41.pdf>, accessed 22 May 2007.

2 A. Sen, 'Population: Delusion and Reality', New York Review of Books 41/15 (1994): 62-71. 
3 E. Renne, 'Anthropological and Public Health Perspectives on the Polio Eradication Initiative in Northern Nigeria', in R. Hahn and M. Inhorn (eds.), Anthropology and Public Health: Bridging Differences in Culture and Society (New York: Oxford University Press, 2009), 512-38. After 2006, ERC reports added "routine immunization" to their titles.

4 World Health Organization, 'Polio Case Count-2011' http://www.who.int/immunization_monitoring/en/ diseases/poliomyelitis/case_count.cfm (accessed 19 April 2012).

5 See W.R. Collis, O. Ransome-Kuti, M. E. Taylor, and L. E. Baker, 'Poliomyelitis in Nigeria', West African Medical Journal, 10 (1961): 217-22. In another study, the local [West African] population was considered to have "natural immunity," H. Gelfand and M. Miller, 'Poliomyelitis in Liberia', American Journal of Tropical Medicine 5 (1956): 791-6.

On 19 July1956, D.J.M. Mackenzie, Director of Medical Services, Northern Region, wrote that: "The Nigerian born and living in Nigeria has a very high rate of immunity against poliomyelitis and their vaccination is unnecessary, except in certain circumstances. The expatriate community, however, is only partially immune and those adults who are not immune are exposed to a serious risk of contracting serious poliomyelitis..." Miscellaneous, 'Salk Anti-Poliomyelitis Vaccine, KAD-MOH 1/18, File MH 5079', (Kaduna: Nigerian National Archives, $1956-$ 1961.

6 J. Paul, A History of Poliomyelitis, (New Haven: Yale University Press, 1971), 8.

7 Gardner-Brown, 26 June 1956, in Miscellaneous, 'Salk Anti-Poliomyelitis Vaccine', 1956-1961; Miscellaneous, 'Poliomyelitis, KAD-MOH, File DIS 14' (Kaduna: Nigerian National Archives, 1947-1957).

8 Seroprevalence studies were conducing in Lagos ('Poliomyelitis in Lagos Area, December 1955', in KAD-MOH 1/18, File MH5079 (Kaduna: Nigerian National Archives, 1956-1961); in Oloibiri (Anonymous, Discussion, Session No. 3. West African Journal of Medicine 10/4 (1961): 229); and Kadandani (Miscellaneous, 'Poliomyelitis in Kadandani, 1956', in KAD-MOH, File MH5079 (Kaduna: Nigerian National Archives, 1956-1961).

9 Collins et al., 'Poliomyelitis in Nigeria', 1961.

$10 \mathrm{~J}$. Familusi and V. Adesina, 'Poliomyelitis in Nigeria: Epidemiological Pattern of the Disease among Ibadan Children', Journal of Tropical Paediatrics and Environmental Child Health 23 (1977): 123.

11 O. Olatimehin, 'Accomplishing the Goal of EPI', National Concord (27 April 1988): 3

12 E. Ekanem, 'A 10-Year Review of Morbidity from Childhood Preventable Diseases in Nigeria: How Successful is the Expanded Programme of Immunization (EPI)?' Journal of Tropical Pediatrics, 34 (1988): 323-28.

13 E. Renne, 'Perspectives on Polio and Immunization in Northern Nigeria', Social Science \& Medicine, 63/7 (2006): 1860.

14 WHA, 'Global Polio Resolution', 1988.

15 E. Renne, The Politics of Polio in Northern Nigeria (Bloomington, IN: Indiana University Press, 2010), 45, 48.

16 A. Jegede, 'What Led to the Nigerian Boycott of the Polio Vaccination Campaign?' PLoS Medicine 4/3|e73 (2007): 0417-22; E. Obadare, 'A Crisis of Trust: History, Politics, Religion and the Polio Controversy in Northern Nigeria', Patterns of Prejudice 39/3 (2005): 265-84; B. Olusanya, 'Polio-Vaccination Boycott in Nigeria', The Lancet 363 (5 June 2004): 1912.

17 E. Renne, 'Anthropological and Public Health Perspectives on the Polio Eradication Initiative in Northern Nigeria', in R. Hahn and M. Inhorn (eds.), Anthropology and Public Health: Bridging Differences in Culture and Society (New York: Oxford University Press, 2009), 512-38.

18 World Health Organization, 'Wild Poliovirus Weekly Update', 26 Nov. 2008'<http://www.polioeradication.org>, accessed 28 Nov. 2008.

19 F. Lazaro, 'Health workers renew fight against polio in Kano', The Online NewsHour, with Gwen Ifill (13 April 2009 ) <http://www.pbs.org/newshour/bb/africa/jan-june09/nigeria_04-13.html>, accessed 20 April 2009; see also M. Yahya, 'Polio Vaccines-"No Thank You!" Barriers to Polio Eradication in Northern Nigeria', African Affairs 106 (2007): 185-204.

${ }^{20}$ National Primary Health Care Development Agency (NPHCDA), Nigeria, '16th Meeting of the Expert Review Committee (ERC) on Polio Eradication \& Routine Immunization in Nigeria, Abuja, 27-28 Oct. 2008' <http:// www.polioeradication.org/Resourcelibrary/Advisoryandcertification/TechnicalAdvisoryGroups.aspx>, accessed 25 Nov. 2011.

21 NPHCDA, '16 ${ }^{\text {th }}$ Meeting, ERC', Oct. 2008.

22 National Primary Health Care Development Agency (NPHCDA), Nigeria, '17th Meeting of the Expert Review Committee (ERC) on Polio Eradication \& Routine Immunization in Nigeria, Ota, Ogun State, 1-2 April 2009' $<$ http://www.polioeradication.org/Resourcelibrary/Advisoryandcertification/TechnicalAdvisoryGroups.aspx $>$, accessed 25 Nov. 2011.

23 World Health Organization, 'Polio This Week', 7 Dec. 2011 http://www.polioeradication.org/Dataandmonitoring/Poliothisweek.aspx, accessed 8 Dec. 2011.

24 I. Mudashir 'Sultan Constitutes Committee on Polio', Daily Trust, (16 June 2009): 6.

25 B. Schimmer and C. Ihekweazu, 'Polio Eradication and Measles Immunisation in Nigeria', The Lancet, 6 (2000): 63-5.

26 E. Renne, unpublished fieldnotes, 30 June 2009. 
27 National Primary Health Care Development Agency (NPHCDA), Nigeria, '11th Meeting of the Expert Review Committee (ERC) on Polio Eradication, Abuja, 7-8 Dec. 2006’ http://www.polioeradication.org/Resourcelibrary/Advisoryandcertification/TechnicalAdvisoryGroups.aspx>, accessed 25 Oct. 2007.

28 In 2008, 74 cases were identified in West Africa (Benin, Burkina Faso, Chad, Cote d'Ivoire, Ghana, Mali, Niger, and Togo), which were genetically linked to the outbreak in northern Nigeria; WHO, Polio Case Count-2008, http://apps.who.int/immunization_monitoring/en/diseases/poliomyelitis/afpextract.cfm, accessed 12 Dec. 2011.

29 J. Lenzer, 'Appeals Court Rules that Nigerian Families can sue Pfizer in US', British Medical Journal, 338 (2009): b458.

30 World Health Organization, 'Cerebrospinal meningitis, Nigeria', Weekly Epidemiological Record 71/10 (1996): 80.

31 Daily Trust, 'Pfizer, Nigeria Sign \$75m Trovan Settlement', Daily Trust (31 July 2009), <http://www.dailytrust.com>, accessed 1 Aug 2009.

32 R. Aliyu, 'Kano Records Low Interest in Immunization', Daily Trust, 25 June 2008, < http://www.dailytrust.com>, accessed 25 June 2008.

33 The ERC noted that "However much the improvement in coverage, particularly in northern states, has been a result of the IPDs...there is not yet a robust programme for the routine delivery of immunization services in several states. Vaccine stock outs remain common." National Primary Health Care Development Agency (NPHCDA), Nigeria, '12th Meeting of the Expert Review Committee (ERC) on Polio Eradication \& Routine Immunization in Nigeria, Abuja, 3-4 May 2007' http://www.polioeradication.org/Resourcelibrary/Advisoryandcertification/ TechnicalAdvisoryGroups.aspx>, accessed 25 October 2007.

34 R. Leo, 'Preventive Medicine is the Way to Go-Pate', Daily Trust, 20 Sept. 2011 <http://www.dailytrust.com>, accessed 20 Sept. 2011. Dr. Pate also spoke at the national ceremony marking the commencement of the national integrated measles campaign.

35 Renne, 'Anthropological and Public Health Perspectives', 527.

36 Z. Bhutta, 'The Last Mile in Global Poliomyelitis Eradication', The Lancet, 378/9791(2011): 549-52.

\section{Bibliography}

Aliyu, R., 'Kano Records Low Interest in Immunization', Daily Trust, 25 June, 2008. [Online]. Retrieved on 25 June 2008 from: <http://www.dailytrust.com>.

Anonymous, 'Discussion, Session No. 3', West African Journal of Medicine, 10/4 (1961): 229.

Bhutta, Z., 'The Last Mile in Global Poliomyelitis Eradication', The Lancet, 378/9791 (2011): 549-52.

Centers for Disease Control and Prevention (CDC), 'Progress Toward Poliomyelitis Eradication-Nigeria, 20052006', Morbidity and Mortality Weekly Report, 56/12 (2007): 278-81.

Centers for Disease Control and Prevention (CDC), 'Polio This Week', 7 Dec., 2011. [Online]. Retrieved on 8 Dec. 2011 from: <http://www.polioeradication.org/Dataandmonitoring/Poliothisweek.aspx>.

Collis, W. R., Ransome-Kuti, O., Taylor, M. E., and Baker, L. E., 'Poliomyelitis in Nigeria', West African Medical Journal, 10 (1961): 217-22.

Daily Trust, 'Pfizer, Nigeria Sign \$75m Trovan Settlement', Daily Trust (31 July 2009). [Online]. Retrieved on 1 Aug. 2009 from: <http://www.dailytrust.com>.

Ekanem, E., 'A 10-Year Review of Morbidity from Childhood Preventable Diseases in Nigeria: How Successful is the Expanded Programme of Immunization (EPI)?', Journal of Tropical Pediatrics, 34 (1988): 323-28.

Familusi, J., and Adesina, V., 'Poliomyelitis in Nigeria: Epidemiological Pattern of the Disease among Ibadan Children,' Journal of Tropical Paediatrics and Environmental Child Health, 23 (1977): 120-4.

Gelfand, H., and Miller, M., 'Poliomyelitis in Liberia,' American Journal of Tropical Medicine, 5 (1956): 791-96.

Jegede, A., 'What Led to the Nigerian Boycott of the Polio Vaccination Campaign?' PLoS Medicine, 4/3|e73 (2007): 0417-22.

Lazaro, F., 'Health Workers Renew Fight Against Polio in Kano', The Online NewsHour, with Gwen Ifill (13 April 2009). [Online]. Retrieved on 20 April 2009 from: <http://www.pbs.org/newshour/bb/africa/jan-june09/nigeria_04-13.html>.

Lenzer, J., 'Appeals Court Rules that Nigerian Families can sue Pfizer in US,' British Medical Journal, 338 (2009): b458.

Leo, R., 'Preventive Medicine is the Way to Go-Pate', Daily Trust, 20 Sept., 2011. [Online]. Retrieved on 20 Sept. 2011 from: <http://www.dailytrust.com>.

Miscellaneous, Poliomyelitis, KAD-MOH, File DIS 14 (Kaduna: Nigerian National Archives, 1947-57).

Miscellaneous, Salk Anti-Poliomyelitis Vaccine, 1956-1961. KAD-MOH 1/18, MH 5079 (Kaduna: Nigerian National Archives, 1956-61).

Mudashir, I., 'Sultan Constitutes Committee on Polio', Daily Trust, 16 June 2009: 6.

National Primary Health Care Development Agency (NPHCDA), Nigeria, '11th Meeting of the Expert Review Committee (ERC) on Polio Eradication, Abuja, 7-8 Dec. 2006'. [Online]. Retrieved on 25 Oct. 2007 from: http://www.polioeradication.org/Resourcelibrary/Advisoryandcertification/TechnicalAdvisoryGroups.aspx $>$. 
National Primary Health Care Development Agency (NPHCDA), Nigeria, 12th Meeting of the Expert Review Committee (ERC) on Polio Eradication \& Routine Immunization in Nigeria, Abuja, 3-4 May 2007'. [Online]. Retrieved on 25 Oct. 2007 from: http://www.polioeradication.org/Resourcelibrary/Advisoryandcertification/ TechnicalAdvisoryGroups.aspx>.

National Primary Health Care Development Agency (NPHCDA), Nigeria, 16th Meeting of the Expert Review Committee (ERC) on Polio Eradication \& Routine Immunization in Nigeria, Abuja, 27-28 Oct. 2008'. [Online]. Retrieved on 25 Nov. 2011 from: http://www.polioeradication.org/Resourcelibrary/Advisoryandcertification/TechnicalAdvisoryGroups.aspx>.

National Primary Health Care Development Agency (NPHCDA), Nigeria, 17th Meeting of the Expert Review Committee (ERC) on Polio Eradication \& Routine Immunization in Nigeria, Ota, Ogun State, 1-2 April 2009'. [Online]. Retrieved on 25 Nov. 2011 from: http://www.polioeradication.org/Resourcelibrary/Advisoryandcertification/TechnicalAdvisoryGroups.aspx>.

National Primary Health Care Development Agency (NPHCDA), Nigeria, Deliberations of the 22nd Meeting of the Expert Review Committee on Polio Eradication in Nigeria (ERC), 13-14 Oct. 2011'. [Online]. Retrieved on 25 November 2011 from: http://www.polioeradication.org/Resourcelibrary/Advisoryandcertification/TechnicalAdvisoryGroups.aspx>.

Obadare, E., 'A Crisis of Trust: History, Politics, Religion and the Polio Controversy in Northern Nigeria', Patterns of Prejudice 39/3 (2005): 265-84.

Olatimehin, O., 'Accomplishing the Goal of EPI', National Concord (27 April 1988): 3.

Olusanya, B., 'Polio-Vaccination Boycott in Nigeria', The Lancet, 363 (5 June 2004): 1912.

Paul, J., A History of Poliomyelitis (New Haven: Yale University Press, 1971).

Renne, E., 'Perspectives on Polio and Immunization in Northern Nigeria', Social Science \& Medicine 63/7 (2006): 1857-69.

Renne, E., 'Anthropological and Public Health Perspectives on the Polio Eradication Initiative in Northern Nigeria', in R. Hahn and M. Inhorn (eds.), Anthropology and Public Health: Bridging Differences in Culture and Society (New York: Oxford University Press, 2009), 512-38.

Renne, E., The Politics of Polio in Northern Nigeria (Bloomington, IN: Indiana University Press, 2010).

Sen, A., 'Population: Delusion and Reality', New York Review of Books, 41/15: 62-71.

Schimmer, B., and Ihekweazu, C. 'Polio Eradication and Measles Immunisation in Nigeria', The Lancet, 6 (2000): 63-5.

World Health Assembly, 'Global Eradication of Poliomyelitis by the Year 2000, Resolution WHA 41.28' (Geneva: WHO, 1988). [Online]. Retrieved on 22 May 2007 from: <http://www.wemos.nl/documents/WHA41.pdf>.

World Health Organization, 'Cerebrospinal meningitis, Nigeria', Weekly Epidemiological Record, 71/10 (1996): 80.

World Health Organization, 'Polio This Week', 7 Dec. 2011. [Online]. Retrieved on 8 Dec. 2011 from: <http:// www.polioeradication.org/Dataandmonitoring/Poliothisweek.aspx $>$.

World Health Organization, 'Polio Case Count-2008', Wild Poliovirus Weekly Update (26 Nov. 2008). [Online]. Retrieved on 28 Nov. 2008 from: <http://www.polioeradication.org/casecount.asp>.

World Health Organization, 'Polio Case Count-2008'. [Online]. Retrieved on 12 Dec. 2011 from: <http://apps. who.int/immunization_monitoring/en/diseases/poliomyelitis/afpextract.cfm.

World Health Organization, 'Polio Case Count-2011'. [Online]. Retrieved on 19 April 2012 from: http:// www.who.int/immunization_monitoring/en/diseases/poliomyelitis/case_count.cfm.

WHO/UNICEF, 'WHO-UNICEF Estimates of Immunization Coverage: Nigeria', World Health Organization, 2007. [Online]. Retrieved on 28 October 2007 from: <http://www.who.int/vaccines/globalsummary/immunization/countryprofileresult.cfm $>$.

Yahya, M., 'Polio Vaccines—“"No Thank You!" Barriers to Polio Eradication in Northern Nigeria', African Affairs, 106 (2007): 185-204. 